\title{
Pessoas com deficiência em tempos de pandemia da COVID- 19: algumas reflexões
}

\author{
People with disabilities in pandemic times of COVID-19: some reflections
}

Personas con discapacidad en tiempos de pandemia de COVID-19: algunas reflexiones

Rosimeire Maria Orlando

Professora doutora da Universidade Federal de São Carlos, São Carlos, SP, Brasil

E-mail: meire_orlando@ufscar.br ORCID: https://orcid.org/0000-0002-0990-6146

Suelen Priscila Ferreira Alves

Mestranda na Universidade Federal de São Carlos, São Carlos, SP, Brasil

E-mail: suelen_ballet@hotmail.com ORCID: https://orcid.org/0000-0001-7695-4693

Silvia Márcia Ferreira Meletti

Professora doutora da Universidade Estadual de Londrina, Londrina, PR, Brasil

E-mail: smeletti@gmail.com ORCID: https://orcid.org/0000-0002-6853-6667

Recebido em 19 de fevereiro de 2021

Aprovado em 01 de junho de 2021

Publicado em 21 de junho de 2021

\section{RESUMO}

A pandemia da COVID-19 acontece em um momento em que diversos países estão apoiados em uma política neoliberal e liderados por governos de extrema direita. O contexto brasileiro faz parte desse cenário mundial, destacando-se entre os países com maior número de casos e mortes. O desmonte do Sistema Único de Saúde (SUS) e da educação pública, anterior à pandemia, ampliaram os desafios para a manutenção da vida e escolarização. Essas condições se agravam ao pensarmos nas pessoas com deficiência. Sendo assim, o objetivo deste estudo é problematizar as condições de vida da população brasileira, principalmente das com deficiência, frente à pandemia e ao impacto na sua escolarização. A pesquisa de cunho descritivo, a partir de dados oficiais do poder público, aponta três pontos para reflexão acerca da pessoa com deficiência no que tange a presença dessa população no espaço geográfico, a relação com os grupos de risco e indicadores de pobreza e extrema pobreza. Por fim, pontuamos os possíveis impactos da pandemia na vida e na escolarização de pessoas com deficiência. Diante das barreiras socioculturais vivenciadas por essa população e de sua invisibilidade, nos dados acerca da pandemia, é extremamente importante nos debruçarmos sobre esta temática para que haja a possibilidade de planejamento e implementação de políticas para garantir a vida e escolarização desta população neste momento.

Palavras-chave: Educação Especial; Pessoas com deficiência; COVID-19. 
http://dx.doi.org/10.5902/1984686X64354

\section{ABSTRACT}

The COVID-19 pandemic comes at a time when several countries are supported by a neoliberal policy and led by far-right governments. The Brazilian context is part of this world scenario, standing out among the countries with the highest number of cases and deaths. The dismantling of the single health system and public education, prior to the pandemic, increased the challenges for maintaining life and schooling. These conditions are aggravated when we think about people with disabilities. Thus, the objective of this study is to problematize the living conditions of the Brazilian population, especially those with disabilities, in the face of the pandemic and the impact on their schooling. The descriptive research based on official data from the public authorities points out three points for reflection about the person with disabilities with regard to the presence of this population in the geographical space, the relationship with risk groups and indicators of poverty and extreme poverty. Finally, we point out the possible impacts of the pandemic on the lives and education of people with disabilities. In view of the socio-cultural barriers experienced by this population and its invisibility, in the data about the pandemic, it is extremely important to address this issue so that there is the possibility of planning and implementing policies to guarantee the life and education of this population at this time.

Keywords: Special Education; Disabled students; COVID-19.

\section{RESUMEN}

La pandemia de COVID-19 llega en un momento en el que varios países cuentan con el apoyo de una política neoliberal y están liderados por gobiernos de extrema derecha. El contexto brasileño forma parte de este escenario mundial, destacándose entre los países con mayor número de casos y muertes. El desmantelamiento del sistema único de salud y la educación pública, antes de la pandemia, aumentó los desafíos para mantener la vida y la educación. Estas condiciones se agravan cuando pensamos en personas con discapacidad. Así, el objetivo de este estudio es problematizar las condiciones de vida de la población brasileña, especialmente de las personas con discapacidad, frente a la pandemia y el impacto en su escolaridad. La investigación descriptiva basada en datos oficiales de los poderes públicos señala tres puntos de reflexión sobre la persona con discapacidad en cuanto a la presencia de esta población en el espacio geográfico, la relación con grupos de riesgo e indicadores de pobreza y pobreza extrema. Finalmente, señalamos los posibles impactos de la pandemia en la vida y educación de las personas con discapacidad. Ante las barreras socioculturales que vive esta población y su invisibilidad, en los datos sobre la pandemia es de suma importancia abordar este tema para que exista la posibilidad de planificar e implementar políticas que garanticen la vida y educación de esta población en este momento.

Palabras clave: Educación Especial; Personas con deficiencia; COVID-19. 
http://dx.doi.org/10.5902/1984686X64354

\section{Introdução}

O presente artigo faz parte de um projeto amplo intitulado Pessoas com Deficiência no Brasil e COVID-19: direitos sociais em foco, somado aos estudos entre os grupos de pesquisa Núcleo de Estudos e Pesquisas em Direito à Educação-Educação Especial/NEPEDEEEs/UFSCar e Núcleo de estudos críticos e pesquisas em educação e desigualdade social, e tem como objetivo problematizar as condições de vida da população brasileira, principalmente das com deficiência, frente à pandemia e ao impacto na sua escolarização. $O$ presente artigo faz parte de um projeto amplo intitulado Pessoas com Deficiência no Brasil e COVID-19: direitos sociais em foco e dos estudos entre os grupos de pesquisa Núcleo de Estudos e Pesquisas em Direito à Educação-Educação Especial/NEPEDE-EEs/UFSCar e Núcleo de estudos críticos e pesquisas em educação e desigualdade social e tem como objetivo problematizar as condições de vida da população brasileira, principalmente das com deficiência, frente à pandemia e ao impacto na sua escolarização.

\section{Pessoas com deficiência e COVID-19 no contexto brasileiro}

Em âmbito mundial, nos últimos anos do século XX e início do século $X X I$ as profundas transformações econômicas, políticas e sociais têm impactado diretamente nas condições de vida das pessoas. Nesse contexto, acrescenta-se a leitura neoliberal que concentra as críticas na suposta expansão desnecessária dos direitos sociais e a participação do Estado, tida como acessória e insuficiente no desenvolvimento de políticas de proteção social (SENNA; COSTA, 2018).

Diante desse cenário, no último dia do mês de dezembro de 2019, a China anuncia um surto de uma doença causada por vírus, com início na cidade de Wuhan. Em 7 de janeiro de 2020 , ela confirma, publicamente, o tratamento de dezenas de pessoas com um surto de pneumonia, e identifica um novo coronavírus como a causa (SACHS, 2020).

Há sete coronavírus humanos (HCoVs) conhecidos, entre eles o SARS-CoV-2, assim denominado pela Organização Mundial de Saúde (OMS). Ele causa a doença COVID-19, cujo nome vem de seu formato redondo e com hastes ao redor, lembrando uma coroa. Coronavírus é uma família de vírus que causa doenças respiratórias. Embora seja antigo, foi isolado em humanos pela primeira vez em 1937 e descrito somente em 1965. Sobre a COVID-19, até o momento pouco se sabe, mas há a certeza da rapidez com que se espalha e sua letalidade, a ponto de em 11 de março de 2020 a OMS decretar estado de pandemia (OPAS, 2020; BRASIL, 2020b). 
http://dx.doi.org/10.5902/1984686X64354

De acordo com o site do Ministério da Saúde (BRASIL, 2020b), o portador da COVID19 pode apresentar um quadro clínico que varia de infecções assintomáticas a quadros respiratórios graves. A maioria pode ser assintomática, uma parte requer atendimento hospitalar por conta da dificuldade respiratória, sendo que aproximadamente $5 \%$ pode requerer suporte ventilatório em leitos de UTI. O diagnóstico deve ser realizado por um profissional da saúde e se embasa em critérios clínicos, laboratoriais e históricos de contato com pessoa infectada. Sua prevenção se dá, basicamente, por ações de higienização, diminuição de contato físico e isolamento social.

O número de pessoas infectadas tem aumentado exponencialmente em âmbito mundial desde o anúncio do surto. Dados de pesquisa de Alves et al. (2020) indicam, até o dia 8 de maio de 2020, os oito países com maior número de casos e óbitos. Até o momento de publicação dos dados, os países com mais casos registrados eram: Estados Unidos 1.292 .917 (76.942 óbitos), Reino Unido 206.715 (30.615 óbitos), Itália 215.858 (29.958 óbitos), Espanha 260.117 (26.299 óbitos), França 174.791 (25.987), Brasil 136.519 (9.265 óbitos), Bélgica 52.011 (8.521 óbitos) e Alemanha 169.430 (7.392 óbitos). Os dados indicavam um total de 3.942.922 de pessoas infectadas no mundo e 271.646 óbitos. Além dos dados confirmarem que o contágio pelo COVID-19 toma conta do mundo, com aumento diário significado, cabe destacar, no âmbito nacional, o baixo índice de testagem da doença no Brasil, apenas 339.552 (ALVES et al., 2020). A baixa cobertura de testes pode ser um indício de prevenção inadequada da epidemia.

No mundo, até 18 de fevereiro de 2021, foram confirmados 109.594 .835 casos de COVID-19, com 2.424.060 óbitos. A Região das Américas é a que se apresentava com maior número de casos confirmados, sendo 48.788 .209 e 1.154.035 óbitos. Os países mais afetados das Américas são os Estados Unidos da América, com 27.491.574 casos confirmados e 484.379 óbitos e o Brasil, com 9.921 .981 e 240.940 óbitos (WHO, 2021).

No contexto nacional, após a confirmação do primeiro caso de COVID-19, em 26 de fevereiro de 2020, na cidade de São Paulo, o vírus, com uma velocidade assustadora, encontrava-se presente em todos os estados, segundo informações repassadas pelas Secretarias Estaduais de todo o país ao Ministério da Saúde. Quase um ano depois, em 18 de fevereiro de 2021, até às 18h00min, o Brasil contava com 9.978.747 casos confirmados de COVID-19 e 242.090 óbitos, sendo que, dos casos confirmados, 8.950.450 foram considerados recuperados e 786.207 se encontravam em acompanhamento. $O$ índice de contaminação a cada 100 mil habitantes foi de 4.748,5 e de letalidade 2,4\% e de mortalidade 
115,2 (BRASIL, 2021). Os estados brasileiros com maior número absoluto de óbitos são: São Paulo, com 57.240 óbitos acumulados, Rio de Janeiro, com 31.882 óbitos acumulados e Minas Gerais, com 17.249 óbitos acumulados.

De acordo com notificações das grandes regiões (BRASIL, 2021), a situação brasileira se encontrava conforme apresentado no Gráfico 1 e Gráfico 2.

Gráfico 1 - Número de casos confirmado por regiões do Brasil

\section{Casos}

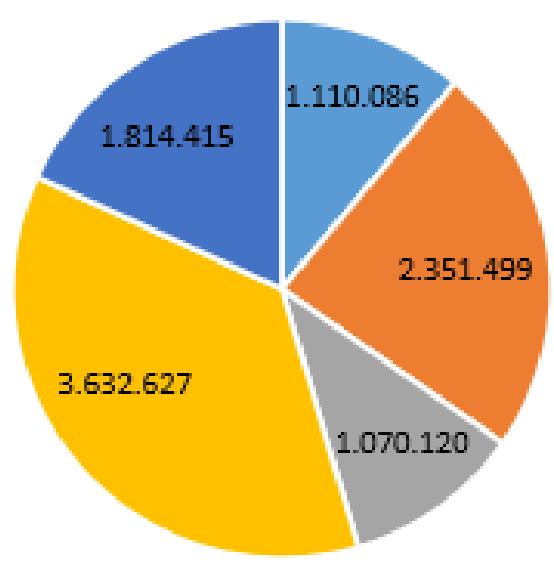

" Região Norte | Região Nordeste " Região Centro-Oeste "Região Suldeste " Região Sul

Fonte: Dados da pesquisa (2021).

Gráfico 2 - Número de óbitos confirmados por regiões do Brasil

\section{Óbitos}

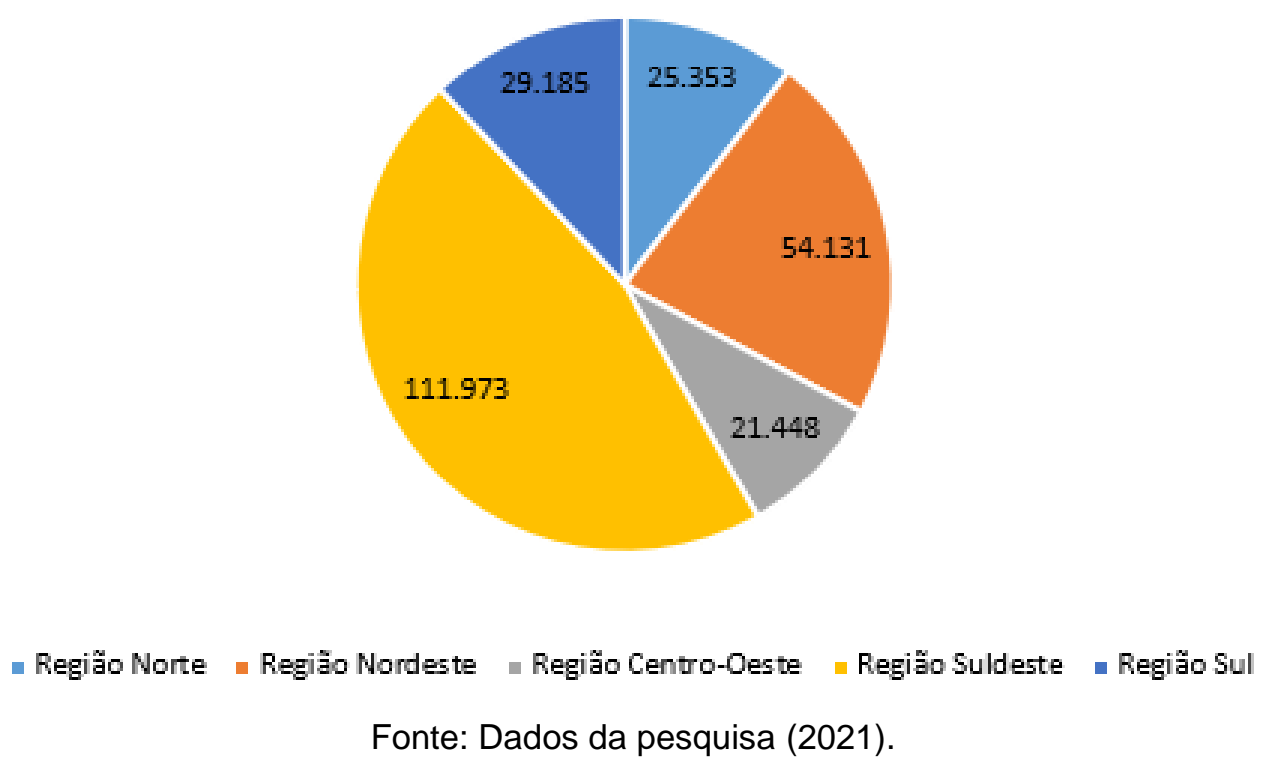

Revista Educação Especial | v. 34 | 2021 - Santa Maria

Disponível em: https://periodicos.ufsm.br/educacaoespecial 
http://dx.doi.org/10.5902/1984686X64354

Tais dados indicam que o momento no Brasil, assim como no mundo, é de alerta para com os cuidados com a manutenção da vida. Cabe destacar que além do registro desse aumento exponencial em curto intervalo de tempo, o Brasil se encontrava nesse período com baixa cobertura de testagem, de acordo com Alves et al. (2020), dada a escassez dos exames. Cabe mencionar ainda que os dados disponíveis até o momento não refletiam com clareza os dados de realidade da epidemia no Brasil, além do fato de a realização tardia dos testes ser fator determinante para resultados falso-negativo.

O isolamento social, etiquetas ao tossir e espirrar, e medidas de higienização com água, sabão e álcool 70\% parecem ser, até o momento, as principais recomendações dos órgãos e autoridades de saúde para prevenção e tentativa de frear a disseminação da doença. Tais ações, à primeira vista simples, em contexto anterior à pandemia já eram particularmente difíceis para grupos em condição de vulnerabilidade social, e se acentuou com a quarentena. Diante deste trágico cenário, Santos (2020) contribui com reflexões importantes ao destacar que toda quarentena é discriminatória e a analisa a partir da perspectiva de grupos em que o sofrimento humano causado pela exploração do sistema capitalista é acentuado, quais sejam: mulheres, trabalhadores precários, informais e autônomos, trabalhadores de rua, moradores de rua, moradores de periferia, os campos de refugiados e imigrantes, os idosos e as pessoas com deficiência ${ }^{1}$. Certo de que o assunto merece reflexão e que o pertencimento em uma condição não necessariamente descarta outra, neste artigo se dará atenção, sobretudo, a essa última população e o impacto da pandemia na escolarização das pessoas com deficiência.

Diante do reconhecimento de que a deficiência precisa de ações coletivas e não mais apenas individuais e de garantia de inserção nas políticas públicas que garantam seu direito à educação - antes da quarentena se iniciou um processo de garantia de direitos à escolarização da pessoa com deficiência em sala de aula comum, em todos os níveis e etapas de ensino - hoje, soma-se um novo desafio para a escolarização desta população diante da pandemia.

\section{Método}

Partimos do reconhecimento de que a sociedade não é homogênea, mas sim antagônica, de modo que a contradição é parte constitutiva da sociedade e das relações que nela se inserem (MARX, 1983). Ademais, trata-se de corroborar a partir da perspectiva dialética de pesquisa em que, aos dizeres de Ferraro (2012, p.144), simplesmente não há 
http://dx.doi.org/10.5902/1984686X64354

quantidade sem qualidade, nem qualidade sem quantidade; a unidade entre essas duas dimensões do real está em sua inseparabilidade ou exigência recíproca, não em qualquer identidade imaginária entre ambas. Essa perspectiva dialética permite afastar duas concepções opostas e igualmente vulneráveis: de um lado, a daqueles(as) que veem incompatibilidade, dicotomia ou oposição excludente entre métodos quantitativos e métodos qualitativos; de outro, a daqueles(as) que veem unidade entre os dois tipos de métodos. Permite, ainda, afastar a tese de um continuum entre quantidade e qualidade, que acaba por restabelecer, nas posições extremas, a dicotomia quantidade-qualidade e, consequentemente, a exclusão mútua entre essas duas dimensões. Nessa direção, o presente estudo, de cunho qualitativo e de caráter descritivo, parte do entendimento de que "há problemas educacionais que para sua contextualização e compreensão necessitam ser qualificados através de dados quantitativos" (GATTI, 2004, p.13). Caracteriza-se como um estudo descritivo que, conforme Gil (2008, p. 28), tem como objetivo principal a "descrição das características de determinada população ou fenômeno ou o estabelecimento de relações entre variáveis".

A presente pesquisa tem como objeto de estudo: 1. Dados consultados no site do Ministério da Saúde, COVID-19 Painel Coronavírus, referente à divulgação dos dados do dia 18 de fevereiro, até às 18h00min. 2. Dados do último Censo Demográfico - IBGE referentes à população total e à população de pessoas com deficiência. 3. Revisão bibliográfica referente à temática.

Os dados quantitativos foram, primeiramente, organizados em tabelas que facilitaram a discussão com base no material bibliográfico.

Nessa direção, a partir de dados oficiais do poder público, apontamos três pontos para reflexão.

\section{1ำ ponto - Presença na população e espaço geográfico}

Segundo a ONU (Organização das Nações Unidas), 1 bilhão de pessoas no mundo possuem alguma condição de deficiência, $80 \%$ vivem nos países em desenvolvimento e $50 \%$ não possui plano de saúde privado.

De acordo com o Censo Demográfico realizado pelo Instituto Brasileiro de Geografia e Estatística (IBGE), em 2010 a população de pessoas com deficiência no Brasil era de 45.606.048 milhões, cerca de 23,9\%. O Censo apontou a presença de pessoas com deficiência em todo o território brasileiro. Em relação à população total, o percentual das 
http://dx.doi.org/10.5902/1984686X64354

pessoas com pelo menos uma das deficiências investigadas foi de 25.800.681 mulheres, cerca de $26,5 \%$ e de 19.805 .367 homens, correspondendo a $21,2 \%$.

Quanto a sua distribuição geográfica, o maior percentual de pessoas com pelo menos uma das deficiências investigadas estava na região Nordeste do país $(26,6 \%)$, seguida das regiões Sudeste $(23,0 \%)$ e Norte $(23,0 \%)$. O menor percentual foi registrado nas regiões Sul $(22,5 \%)$ e Centro Oeste (22,5\%) (IBGE, 2010).

Verifica-se que os dados apontam a presença de pessoas com deficiência em todo território brasileiro e sua presença maior em três grandes regiões - Nordeste, Sudeste e Norte. Conforme apontado nos parágrafos acima, as regiões em que o vírus mais tem causado contágio e óbitos são as regiões Sudeste, Nordeste e Norte. A reflexão merece aprofundamento, mas cabe levantar o fato de que de acordo com o Censo Demográfico de 2010, dos 20,2 milhões de habitantes da região metropolitana de São Paulo (região com maior índice de contágio do vírus e óbitos registrados no Brasil), 5,6 milhões são migrantes, ou seja, $28 \%$ da população, e os estados que mais fornecem migrantes para a cidade de São Paulo, são Bahia, Pernambuco e Ceará, estados do Nordeste brasileiro.

Diante da presença da pessoa com deficiência na sociedade, cabe problematizarmos: Com a pandemia instalada no território brasileiro, quais ações o Estado tem feito para assegurar as condições de escolarização desta população?

\section{2ำ ponto - Grupos de risco}

Diante da gravidade do COVID-19, são considerados grupos de risco pessoas com mais de 60 anos, pessoas com doenças pré-existentes como diabetes, cardiopatia, doenças neurológicas, imunodepressão, obesidade, asma, doença renal, entre outras, talvez possamos considerar neste montante um número considerável de pessoas com deficiência.

De acordo com dados do censo demográfico (IBGE, 2010), o percentual de pessoas com deficiência na população residente, segundo grupos de idade, é de $7,5 \%$ de 0 a 14 anos de idade, $24,9 \%$ de 15 a 64 anos e $67,7 \% 65$ anos ou mais de idade.

Analisando a composição dos dados por idade das pessoas com deficiência, percebese um aumento da população a partir dos 15 anos, com uma concentração maior nos sujeitos com mais de 64 anos. O maior grupo da população com pelo menos uma das deficiências investigadas ocorreu na população de 40 a 59 anos, num total de 17.435.955 pessoas. Para esse grupo etário, a deficiência visual foi o tipo mais declarado, seguido das 
http://dx.doi.org/10.5902/1984686X64354

deficiências motora e auditiva (IBGE, 2010). De acordo com o Relatório Mundial sobre Deficiência (BRASIL, 2012), pesquisas indicam que adultos com deficiência de desenvolvimento apresentam problemas crônicos de saúde, como hipertensão, doença cardiovascular e diabetes, igual ou maior do que pessoas sem deficiência.

De acordo com estudos recentes, as pessoas com deficiência podem estar mais vulneráveis ao vírus. Para Senjam (2020), as pessoas com deficiência visual podem estar mais vulneráveis à COVID-19, por falta de informações acessíveis para essa população, pela necessidade de apoio de terceiros em alguns momentos, por falta de conhecimentos adequados sobre o uso correto das máscaras ou cuidados de higiene em geral, pela necessidade do toque para atividades de rotina, pelas barreiras para o acesso à saúde e educação anteriores à pandemia.

As pessoas com deficiência intelectual também podem apresentar maior vulnerabilidade ao vírus. Durante a epidemia de gripe de 2017-2018, na Holanda a mortalidade excessiva entre as pessoas com deficiência intelectual foi três vezes maior comparado à população em geral. Para Cuypers et al. 2020, esses dados sugerem que a pandemia da COVID-19 pode afetar de forma desproporcional à essa população. Segundo De Cauwer e Spaepen (2020), pessoas com Síndrome de Down têm riscos maiores de morte para $\mathrm{H} 1 \mathrm{~N} 1$, o que traz importantes reflexões para essa pandemia. No relato desses autores sobre a COVID-19 em pessoas com Síndrome de Down, de quatro pacientes detectados com a doença, três necessitaram atendimento hospitalar e um foi levado a óbito, todos desenvolveram a forma mais grave da doença.

Diante dos estudos encontrados até o momento e das especificidades de cada pessoa com deficiência, cabe questionarmos: Como se dá a articulação intersetorial para a garantia de direitos sociais desta população? Que redes de informação e de proteção, até o momento, estão sendo disponibilizadas para essas pessoas?

\section{3ำ ponto - Indicadores de pobreza e extrema pobreza}

De todo modo, dados dos indicadores de pobreza no Brasil e no mundo são alarmantes e impactam diretamente nas condições de vida da população. Conforme aponta o Banco Mundial (Banco Mundial, 2018), em 2015 46\% da população mundial vivia com menos de US\$ 5,50 por dia, ou seja, quase metade da população mundial, cerca de 3,4 bilhões de pessoas, ainda não têm condições monetárias de satisfazer suas necessidades básicas. 
http://dx.doi.org/10.5902/1984686X64354

Certo é que tanta desigualdade social não se caracteriza apenas pelo seu caráter monetário, associado à baixa renda estão o desemprego, a fome, a falta de saneamento básico e moradia, ausência ou precariedade dos serviços de saúde, transporte, educação, entre outros. O Brasil é conhecido por manter uma das mais altas taxas de desigualdade de renda do mundo. Dados apresentados por Hecksher, Silva e Corseuil (2018) apontam que além da renda nacional ser concentrada nos estratos mais abastados, os $10 \%$ mais ricos respondem por $51,5 \%$ da desigualdade total. Isso significa que o décimo mais rico dos brasileiros contribui para mais da metade da medida total de desigualdade.

No Brasil, outros dados também revelam preocupação, pois de acordo com dados divulgados pelo IBGE, como parte da Síntese de Indicadores Sociais no Brasil (IBGE/SIS, 2018) que analisa a pobreza sob a ótica monetária, em 2017 cerca de 55 milhões (26,5\%) de pessoas viviam na linha da pobreza, ou seja, embora haja discussões sobre as linhas de corte, o documento aponta que elas sobreviviam com renda familiar de $\mathrm{R} \$ 406,00$ mensais (valores em 2017). Em 2016, eram cerca de 25,7\% da população. A maior concentração, cerca de 25 milhões (44,8\%), estava na região Nordeste, a região Sul registrou a menor concentração $12,8 \%$, na região Sudeste houve um aumento, de 16,1\% para $17,4 \%$ e na região Centro Oeste chegou a 16,9\%.

A pandemia causada pela COVID-19 é elemento novo no complexo e intrincado cenário mundial e nacional, a escalada da doença causada pelo novo coronavírus, em uma magnitude não conhecida por esta geração, é efetivamente chocante. Desde a década de 1980, com o avanço do neoliberalismo como a versão dominante do capitalismo e à medida que foi se sujeitando à lógica do setor financeiro, o mundo tem experimentado cada vez mais uma crise permanente (TOSTES; MELO FILHO 2020; SANTOS, 2020).

Diante deste contexto, os fatores socioeconômicos influenciam na progressão dos casos confirmados da COVID-19. Em abril, Fortes, Oliveira e Sousa (2020) já apresentavam que regiões como a Baixada Fluminense poderiam sentir muito mais os impactos da COVID-19. A região é caracterizada por uma ampla população, condições precárias de vida, dificuldades econômicas e de moradia que dificultam também a adoção de medidas preventivas como o distanciamento social. Batista et al. (2020) analisaram os dados das notificações da Síndrome Respiratória Aguda Grave atualizados até 18 de maio de 2020 no Brasil. De acordo com os resultados dos autores, pessoas pretas e pardas sem escolaridade apresentaram proporção 4 vezes maior de letalidade quando comparadas a 
http://dx.doi.org/10.5902/1984686X64354

pessoas brancas com nível superior de ensino. As desigualdades de renda são refletidas também no acesso à saúde.

Problematizando essa realidade, de acordo com Orlando e Caiado (2014), o Censo Demográfico (BRASIL, 2010) aponta que no Brasil, 26,15\% das pessoas com deficiência com 10 anos ou mais sobrevive com 1 a 5 salários mínimos, 22,82\% não possuem rendimento e a maior parte, $47,5 \%$ sobrevive com a renda de até 1 salário mínimo.

Diante deste quadro, pode-se verificar que, dadas as condições concretas de um país marcado pela desigualdade social, pelo elevado número de pessoas em condições de pobreza e extrema pobreza e que o quadro se acentua quando se agrega a condição de deficiência, há muito que se preocupar quando se soma uma pandemia. Diante desta realidade, cabe problematizarmos: Frente à pandemia, que políticas sociais vêm sendo implementadas, efetivamente, para esta população?

\section{Impactos da pandemia na vida e na escolarização de pessoas com deficiência}

Os três pontos apresentados permitem refletir sobre o impacto da pandemia na escolarização das pessoas com deficiência.

A Educação Especial no Brasil se construiu com base em um processo de segregação, com uma política de cunho assistencialista, filantrópica e não universal, marcada pela desresponsabilização do Estado para com a educação das pessoas com deficiência. Hoje, apesar de alguns avanços, o discurso da solidariedade e responsabilidade social para com as pessoas com deficiência ainda é reforçado pela peculiaridade assistencialista (MICHELS, 2002).

Dados referentes à escolarização da população brasileira, coletados por meio de inquérito amostral, de acordo com dados do Censo Demográfico (IBGE, 2010), indicam um total de 4.760.548 estudantes, cerca de 2,49\%, que indicaram estar cursando a Educação Básica e 553.622 a Educação Superior, representando 0,29\%. Se cotejarmos esses dados em relação ao número de pessoas que indicaram possuir algum tipo de deficiência, 159.992, 0,08\%, apontam estar na Educação Básica e 36.288, apenas 0,01\%, na Educação Superior. Baseados no Censo Escolar no período de 1997 a 2006, Bueno e Meletti (2011) demonstram que os dados de matrícula na Educação Especial, de acordo com o tipo de escolarização oferecido, apesar da tendência crescente de matrículas na Educação Especial, ano a ano, totalizando um aumento de 48,14\%, ainda estavam aquém da demanda quando comparados 
http://dx.doi.org/10.5902/1984686X64354

com o número total de matrículas na escola básica. Ou seja, verifica-se a presença de uma baixa porcentagem da população em todo o processo de escolarização, e quando a atenção se volta para as pessoas com deficiência, o quadro se agrava.

A pandemia escancara as desigualdades no processo de escolarização dos brasileiros. O desmonte da educação pública nessa ordem econômica neoliberal anterior à pandemia somado às diferenças regionais e à extrema desigualdade social dificultam as possibilidades de escolarização nesse período. Uma das medidas tomada pelo governo foi a flexibilização dos dias letivos a partir de primeiro de abril de 2020, com a Medida Provisória n 934, que garante no artigo 1 que

O estabelecimento de ensino de educação básica fica dispensado, em caráter excepcional, da obrigatoriedade de observância ao mínimo de dias de efetivo trabalho escolar, nos termos do disposto no inciso I do caput e no $\S 1^{\circ}$ do art. 24 e no inciso II do caput do art. 31 da Lei no 9.394, de 20 de dezembro de 1996, desde que cumprida a carga horária mínima anual estabelecida nos referidos dispositivos, observadas as normas a serem editadas pelos respectivos sistemas de ensino (BRASIL, 2020a, p. 1).

A partir dessa flexibilização nos dias letivos, alguns estados começaram a discutir a possibilidade de atividades remotas. De acordo com Saviani (2020), o ensino remoto é diferente do Ensino a Distância, pois não preenche as condições mínimas para essa modalidade de ensino. O autor também evidencia a falta de condição da maioria dos alunos e professores para ter acesso a essas atividades emergenciais. O papel social da escola é extremamente importante para a formação humana, ao voltar nossa atenção para questões referentes às pessoas com deficiência, é certo que o ensino remoto não pode ser equiparado ao ensino regular pelas condições de vida dos estudantes e professores. Por outro lado, este ensino tem viabilizado a presença da escola na vida dos estudantes que têm condições de acesso (SOUZA; DAINEZ, 2020).

As possibilidades de ensino-aprendizagem através do ensino remoto tornam-se ainda mais escassas para estudantes com deficiência e em vulnerabilidade social.

Aos dizeres de Saviani (2021),

No "ensino" remoto, ficamos com pouco ensino, pouca aprendizagem, pouco conteúdo, pouca carga-horária, pouco diálogo. Em contrapartida, temos muitas tarefas. Do lado dos alunos, estes supostamente passam a ser "autônomos" e vão em busca do próprio conhecimento, assoberbados com a multiplicação de leituras, vídeos, podcasts, webinários etc. (SAVIANI, 2021, p. 42).

A realidade concreta vivenciada pela população brasileira sem e com deficiência em tempos de pandemia causada pela COVID-19 anuncia desafios que, certamente, impactarão 
http://dx.doi.org/10.5902/1984686X64354

no período pós-pandemia, somados à pressão para a generalização da educação a distância em função de interesses econômicos privados e fruto de uma intensa irresponsabilidade com a educação pública de qualidade e pela apatia de vários setores ligados a movimentos sociais que apoiam o ensino virtual (SAVIANI, 2021).

De acordo com Silva, Bins e Rozek (2020), a pandemia escancara as desigualdades já existentes e a necessidade de políticas direcionadas para a educação especial. As pessoas com deficiência estão sendo invisibilizadas mais uma vez, poucos estudos são encontrados na área, por exemplo, no município de Fortaleza os professores do Atendimento Educacional Especializado relataram escassez de orientações (OLIVEIRA NETA; NASCIMENTO; FALCÃO, 2020). Os documentos não atendem às necessidades das pessoas com deficiência e não garantem as condições materiais, aqueles com propostas específicas para educação especial se distanciam das propostas para a educação básica em geral e tratam a pessoa com deficiência a partir de uma concepção biologizante (OZÓRIO et al., 2020; CONDE; CAMIZÃO; VICTOR, 2020). As famílias de estudantes com deficiência têm encontrado dificuldades para acompanhá-los nas atividades desenvolvidas no ensino remoto. De acordo com Carvalho et al. (2020), a mães de crianças de seis a doze anos estão tendo dificuldades para auxiliarem os filhos com as atividades escolares durante a pandemia.

Sintetizando, se tomarmos o que foi apresentado anteriormente neste artigo, alguns dados nos saltam aos olhos.

1. Ordem das regiões brasileiras com maior número de pessoas contaminadas com COVID-19 e óbitos: Sudeste, Nordeste, Norte, Sul e Centro Oeste. Com destaque para a alta porcentagem de nordestinos migrantes na cidade de São Paulo, cidade com maior registro de contaminação por COVID-19 e óbitos.

2. Ordem das regiões brasileiras com maior número de pessoas com deficiência: Nordeste, Sudeste, Norte, Sul e Centro Oeste.

3. Grupo de risco e pessoas com deficiência: a maioria da população residente com pelo menos uma das deficiências indicadas se encontra na faixa etária dos 40 aos 59 anos e com 65 anos ou mais de idade e podem apresentar problemas crônicos de saúde, como hipertensão, doença cardiovascular e diabetes.

4. Desigualdade social e deficiência: um número considerável de pessoas com deficiência se encontram na faixa da pobreza e extrema pobreza. Boa parte não possui rendimentos ou vive com apenas um salário mínimo. 
http://dx.doi.org/10.5902/1984686X64354

5. Adesão ao ensino remoto durante a pandemia: as pessoas com deficiência na faixa da pobreza e extrema pobreza podem não estar tendo acesso aos conteúdos disponibilizados no ensino remoto. A falta de condições materiais para acessar as aulas, falta de conhecimento dos professores para adaptar esses materiais para esse ambiente e a falta de pessoas próximas com condição de tempo e conhecimento para auxiliar esses estudantes são apenas algumas das variáveis que podem interferir no processo de escolarização nesse tempo.

6. Retorno para as escolas: como apontado pelos estudos, as pessoas com deficiência podem estar mais vulneráveis ao vírus, sejam por comorbidades associadas, formas de interação, deslocamento ou pela necessidade de profissionais de apoio. O retorno às escolas para essa população pode ser um pouco mais demorado.

Assim, as pessoas com deficiência estão presentes em todo território nacional e se encontram dentro do grupo de risco da COVID-19. As residentes nas regiões Nordeste, Sudeste e Norte parecem requerer cuidado redobrado, dado o número de pessoas com deficiência e o número de contaminação e óbitos nestas localidades. Quando se agrega a este grupo a questão da pobreza e extrema pobreza, tudo indica que o cuidado precisa ser triplicado, sobretudo com a região Nordeste.

Em se tratando desse público, tudo indica que terão fortes impactos em seu processo de escolarização, pois fica claro que, como afirma Martins (2002), a sociedade exclui para incluir e ao incluir o faz de uma maneira desumana, precária, e a escola, enquanto parte integrante deste sistema, como afirmam Marin e Albuquerque (2010), persevera em um modo de ser e deixa de atender a efetivação de uma escola que cumpre sua função de contribuir para que os alunos se apropriem, efetivamente, dos saberes escolares.

\section{Algumas considerações}

No momento atual, diante do quadro de pandemia por conta do COVID-19 o mundo se encontra em estado de alerta e o Brasil não escapa dessa realidade, pois tem apresentado um aumento diário no registro de casos confirmados e de óbitos, fato que o situa em fase de crescimento exponencial. O mundo está em alerta.

Mais do que respostas prontas, o presente artigo objetivou trazer elementos para reflexão sobre esta realidade e apontar questionamentos para aprofundamento. A população mundial, a brasileira e, em especial, as pessoas com deficiência precisam ser entendidas 
http://dx.doi.org/10.5902/1984686X64354

como sujeitos concretos inseridos em condições sociais complexas e ressalta-se aqui a importância de uma rede de proteção social.

Considerando as barreiras socioculturais que impedem o exercício dos direitos básicos dessa população, se destaca a necessidade de pesquisas que possam contribuir para a formulação, estruturação e concretização de políticas públicas e garantia de inserção desse público em todas as dimensões da vida social e, em especial, sua garantia à escolarização.

Dada a importância da articulação intersetorial na garantia dos direitos sociais dessas pessoas e sobretudo com o agravamento da pandemia, se destaca a importância de pesquisas sobre as condições concretas de vida delas frente a esta nova realidade.

Finalizando, a falta de estatísticas sobre as pessoas com deficiência na pandemia contribui para a invisibilidade dessas pessoas, e isso representa um obstáculo imenso para o planejamento e a implementação de políticas sociais que contribuam, neste contexto, para além da escolarização, a sobrevivência dessas pessoas. De todo modo, para finalizar, esperamos que as pesquisas, inclusive na área de humanas, sejam tão velozes quanto o vírus.

\section{Referências}

ALVES, Cláudia Regina Lindgren et al. Por que ainda não é o momento para flexibilizar o Isolamento Social em Minas Gerais? 9 argumentos com embasamento científico. Comitê Permanente de enfrentamento do Novo Coronavírus da UFMG. 2020.

BANCO MUNDIAL. Quase Metade do Mundo Vive com Menos de USD \$5.50 por Dia. Disponível em: https:/www.worldbank.org/pt/news/pressrelease/2018/10/17/nearly-half-theworld-lives-on-less-than-550-a-day-brazilian-portuguese. Acesso em: 08 out. 2019.

BRASIL. Relatório mundial sobre a deficiência (World Health Organization, The World Bank). Tradução de Lexicus Serviços Linguísticos. São Paulo: SEDPcD, 2012. 334 p.

BRASIL. Lei no 13.146, de 6 de Julho de 2015. Institui a Lei Brasileira de Inclusão da Pessoa com Deficiência (Estatuto da Pessoa com Deficiência). Disponível em: http://www.planalto.gov.br/ccivil_03/_ato2015-2018/2015/lei/l13146.htm. Acesso em: 11 maio 2020.

BRASIL. Medida provisória nำ 934, de 1ํ de Abril de 2020. Estabelece normas excepcionais sobre o ano letivo da educação básica e do ensino superior decorrentes das medidas para enfrentamento da situação de emergência de saúde pública de que trata a Lei no 13.979, de 6 de fevereiro de 2020. Diário Oficial da União, Brasília, DF, 01 abr. 2020a. Seção 1, p. 1. 
http://dx.doi.org/10.5902/1984686X64354

BRASIL. Ministério da Saúde. Sobre a Doença. Disponível em: https://coronavirus.saude.gov.br/sobre-a-doenca\#o-que-e-covid. Acesso em: 11 maio $2020 b$.

BRASIL. Ministério da Saúde. COVID-19 Painel Coronavírus. Disponível em: https://covid.saude.gov.br. Acesso em: 18 fev. 2021.

BATISTA, Amanda et al. Análise socioeconômica da taxa de letalidade da COVID-19 no Brasil - Nota Técnica 11. Núcleo de Operações e Inteligência em Saúde 2020; 25 mai. Disponível em:

https://drive.google.com/file/d/1tSU7mV4OPnLRFMMY47JIXZgzkklvkydO/view Acesso em: 06 out. 2020.

BUENO, José Geraldo Silveira; MELETTI, Silvia Márcia Ferreira. Educação infantil e educação especial: uma análise dos indicadores educacionais brasileiros. Contrapontos, v.11, p. 65-80, 2011. Disponível em:

https://siaiap32.univali.br/seer/index.php/rc/article/view/2938. Acesso em: 06 nov. 2020.

CARVALHO, Carla Beatriz et al. Ensino Remoto e Necessidades Específicas: o papel da escola e das famílias. Braz. J. of Develop. Curitiba, v.6, n.10, p.74345-74355, out. 2020. Disponível em: https://www.brazilianjournals.com/index.php/BRJD/article/view/17636/14315. Acesso em: 17 maio 2021.

CONDE, Patricia Santos; CAMIZÃO, Amanda Costa; VICTOR, Sonia Lopes. Pandemia e atividades remotas: possibilidades e desafios para a educação especial. Revista Cocar. v.14 n.30 set./dez. p.1-16, 2020. Disponível em:

https://periodicos.uepa.br/index.php/cocar/article/view/3744. Acesso em: 17 maio 2021.

CUYPERS, Maarten et al. Mortality of people with intellectual disabilities during the 2017/2018 influenza epidemic in the Netherlands: potential implications for the COVID-19 pandemic. Journal of Intellectual Disability Research, v.64, n.7, p. 482-488, jul. 2020. Disponível em: https://onlinelibrary.wiley.com/doi/full/10.1111/jir.12739. Acesso em: 29 ago. 2020.

DE CAUWER, Harald; SPAEPEN, Ann. Are patients with Down syndrome vulnerable to lifethreatening COVID-19? Acta Neurologica Belgica, p. 1-3, maio 2020. Disponível em: https://www.ncbi.nlm.nih.gov/pmc/articles/PMC7243430/\#: :text=Patients\%20with\%20Down \%20syndrome\%20are,an\%20outbreak\%20of\%20COVID\%2D19. Acesso em: 29 ago. 2020.

FERRARO, Alceu Ravanello. Quantidade e qualidade na pesquisa em educação, na perspectiva da dialética marxista. Pro-Posições, Campinas, v.23, n.1, p. 129-146, abril de 2012. Disponível em: http://www.scielo.br/scielo.php?script=sci_arttext\&pid=S010373072012000100009\&Ing=en\&nrm=iso. Acesso em: 18 de fev. 2021.

FORTES, Alexandre; OLIVEIRA, Leandro Dias de; SOUSA, Gustavo Mota. A COVID-19 na Baixada Fluminense: Colapso e apreensão a partir da periferia metropolitana do Rio de Janeiro. Espaço e Economia [on-line], v.18, p. 1-19, 2020. Disponível em: https://journals.openedition.org/espacoeconomia/13591. Acesso em: 17 jun. 2020.

GATTI, Bernadete Angelina. Estudos quantitativos em educação. Educação e Pesquisa, São Paulo, v. 30, n. 1, p. 11-30, jan-abr. 2004. 
http://dx.doi.org/10.5902/1984686X64354

GIL, A. C. Natureza das ciências sociais. In: GIL, A. C. Métodos e técnicas de pesquisa social. 6. São Paulo: Atlas, 2008.

HECKSHER, Marcos; SILVA, Pedro Luis do Nascimento; CORSEUIL, Carlos Henrique. A contribuição dos ricos para a desigualdade de renda no Brasil. IPEA. Texto para discussão. Brasília 2018. Disponível em:

http://repositorio.ipea.gov.br/bitstream/11058/8695/1/td_2411.pdf. Acesso em: 06 nov. 2020.

IBGE. Censo Demográfico. Disponível em:

file:///E:/Coleta_p\%C3\%B3s\%20doc/Extra\%C3\%A7\%C3\%A30\%20dados\%20Sidra_IBGE/D ados\%20IBGE/censo_demogr\%C3\%A1fico_2010.pdf. Acesso em: 11 maio 2020.

MARIN, Alda Junqueira; ALBUQUERQUE, Helena Machado de Paula. Facetas de formas de organização escolar e presença da exclusão na escola In: MARIN, Alda Junqueira; BUENO, José Geraldo Silveira (Org.). Excluindo sem saber. Araraquara, SP: Junqueira \& Marin; Brasília, DF: CNPQ, 2010.

MARTINS, José de Souza. A sociedade vista do abismo: novos estudos sobre exclusão, pobreza e classes sociais. Petrópolis, RJ: Vozes, 2002.

MARX, Karl. Contribuição à crítica da economia política. Tradução de Maria Helena B. Alves. São Paulo: Martins Fontes, 1983.

MICHELS, Maria Helena. Caminhos da exclusão: a política para a educação e a educação especial nos anos de 1990. Ponto de Vista, Florianópolis, n.3/4, p. 073-086, 2002.

Disponível em: file:///C:/Users/PC/Downloads/1313-4987-1-PB.pdf. Acesso em: 06 out. 2020.

OLIVEIRA NETA, Adelaide de Sousa; NASCIMENTO, Romária de Menezes do; FALCÃO, Giovana Maria Belém. A educação dos estudantes com deficiência em tempos de pandemia de covid-19: a invisibilidade dos invisíveis. Interacções, v.16, n.54, p. 25-48, 2020. Disponível em: https://revistas.rcaap.pt/interaccoes/article/view/21070. Acesso em: 17 maio 2021.

OPAS - Organização Panamericana de Saúde. Folha informativa COVID-19 - Escritório da OPAS e da OMS no Brasil. Disponível em:

https://www.paho.org/bra/index.php?option=com_content\&view=article\&id=6101:covid $19 \&$ It emid=875\#recomendacoes. Acesso em: 11 maio 2020.

ORLANDO, Rosimeire Maria; CAIADO, Katia Regina Moreno. Professores Universitários com Deficiência: trajetória escolar e conquista profissional. Educação \& Realidade, Porto Alegre, v.39, n.3, p. 811-830, jul./set. 2014. Disponível em:

https://seer.ufrgs.br/index.php/educacaoerealidade/article/view/45620. Acesso em: 06 out. 2020.

OZÓRIO, Francisca Janaina Dantas Galvão et al. Políticas públicas para o atendimento educacional especializado em Fortaleza durante a pandemia. Rev. Pemo, v.3, n.1, p. 313 864, 2020. Disponível em:

https://revistas.uece.br/index.php/revpemo/article/view/3864. Acesso em: 22 mar. 2021. 
SACHS, Jeffrey. Por que a covid-19 se alastra nos EUA e o que pode ser feito? In: TOSTES, Anjuli; MELO FILHO, Hugo. Quarentena: reflexões sobre a pandemia e depois. 1.ed. - Bauru: Canal 6, 2020.

SANTOS, Boaventura de Sousa. A cruel Pedagogia do vírus. Edições Almedina, S.A. Portugal, 2020.

SAVIANI, Dermeval. Crise estrutural, conjuntura nacional, coronavírus e educação - 0 desmonte da educação nacional. Revista Exitus, [S. I.], v.10, n.1, p. e020063, 2020. DOI: 10.24065/2237-9460.2020v10n1ID1463. Disponível em:

http://www.ufopa.edu.br/portaldeperiodicos/index.php/revistaexitus/article/view/1463. Acesso em: 23 ago. 2020.

SAVIANI, Dermeval; GALVÃO, Ana Carolina. Educação na pandemia: a falácia do "ensino" remoto. Universidade e Sociedade, n.67, p. 36-49, 2021. Disponível em: https://www.andes.org.br/img/midias/66ab954ec8f021a1b9ee3f68b131266d_161167255 5.pdf. Acesso em: 14 maio 2021.

SENNA, Mônica de Castro Maia; COSTA, Brenda Luana Silva. Famílias e Assistência Social: reflexões sobre o BPC e o PBF. Em Pauta, v.16, n.42, p. 109-124, 2º semestre de 2018.

SENJAM, Suraj Singh. Impact of COVID-19 pandemic on people living with visual disability. Indian J Ophthalmol, v.68, n.7, p. 1367-1370. Disponível em:

http://www.ijo.in. Acesso em: 28 ago. 2020.

SILVA, Karla Wunder da; BINS, Katiuscha Lara Genro; ROZEK, Marlene. A educação especial e a covid-19: aprendizagens em tempos de isolamento social. Interfaces Científicas - Educação, [S. I.], v. 10, n. 1, p. 124-136, 2020. Disponível em: https://periodicos.set.edu.br/educacao/article/view/8914. Acesso em: 21 mar. 2021

SOUZA, Flavia Faissal de; DAINEZ, Débora. Educação especial e inclusiva em tempos de pandemia: o lugar de escola e as condições do ensino remoto emergencial. Práxis Educativa, Ponta Grossa, v.15, p. 1-15, 2020. Disponível em:

https://revistas2.uepg.br/index.php/praxiseducativa/article/view/16303. Acesso em: 17 out. 2020.

TOSTES, Anjuli; MELO FILHO, Hugo. Quarentena: reflexões sobre a pandemia e depois. Bauru: Canal 6, 2020.

WHO - World Health Organization. Coronavírus Disease (COVID-19). Situation Report 156, 24 de Jun. 2020. Disponível em: https://covid19.who.int/. Acesso em: 18 fev. 2021. 


\section{Notas}

${ }^{1}$ Considera-se pessoa com deficiência aquela que tem impedimento de longo prazo de natureza física, mental, intelectual ou sensorial, o qual, em interação com uma ou mais barreiras, pode obstruir sua participação plena e efetiva na sociedade em igualdade de condições com as demais pessoas (BRASIL, 2015).

\section{(c) () (9)} 4.0 International (CC BY-NC 4.0) 